\title{
Behavioral Characteristics and Psychological Profil of PRADER WILLI Syndrome: A Case Report
}

\author{
Rabitateddine M $^{*}$, Amraouza K, Ennazk S, Sak H, Adali I, Manoudi F, Asri F
}

Reseach Team for Mental Health; Mohammed VI University hospital Center, Marrakesh-Morocco

DOI: $10.36347 /$ simcr.2020.v08i02.036

| Received: 18.02.2020 | Accepted: 25.02.2020 | Published: 27.02.2020

*Corresponding author: Rabitateddine $\mathrm{M}$

Abstract

Case Report

Prader-Willi syndrome (PWS) is a neurodevelopmental disability characterized by hypotonia and failure to thrive during infancy, then the development of hyperphagia, hypogonadism, cognitive impairments and distinct physical and behavioral characteristics. Through our patient's case and literature review, we're willing to showcase the different psychiatric disorders that can occur in patients with PWS, and show treatments that are specific and/or effective. Our patient is a 19 year old Caucasian male, diagnosed with Prader-Willi syndrome through its clinical elements, has also type 1 diabetes and sent by the endocrinology unit to the psychiatry department to take charge its behavioral disorders. Several studies investigating social and communication skills have shown people with PWS to have difficulties with care, receptive and expressive language skills, interpreting emotional valence in faces, understanding personal space and a developmental delay in theory of mind. Temper outbursts, temper tantrums and skin picking are often seen in PWS. Different drugs can be used such as second generation of anti-pyschotics, antidepressants and oxytocin and others.

Keywords: Prader-Willi, psychiatric symptoms, genetic, pharmacology.

Copyright @ 2020: This is an open-access article distributed under the terms of the Creative Commons Attribution license which permits unrestricted use, distribution, and reproduction in any medium for non-commercial use (NonCommercial, or CC-BY-NC) provided the original author and source are credited.

\section{INTRODUCTION}

Prader-Willi syndrome (PWS) is a neurodevelopmental disability characterized by hypotonia and failure to thrive during infancy, then the development of hyperphagia, hypogonadism, cognitive impairments and distinct physical and behavioral characteristics. The syndrome is due to a deficiency of paternally expressed genes on chromosome 15 q11-q13. It affects $1 / 15000$ births with equal distribution in both sexes and all ethnic groups [1].

Psychiatric comorbidity can occur in persons with Prader-Willi syndrome varying from emotional and behavioural disorders [2].

\section{Case Report}

Mr H.D is a 19 year old Caucasian male, the youngest of his four siblings, diagnosed with PraderWilli syndrome through its clinical elements: hypotonia during neonatal period, hypotrophy, and the delay of acquisition of walking (till the age of 3 years old), dysarthria and recurrent respiratory infections due to the weakness of respiratory muscles. Our patient has also a dismorphic syndrome including a narrow front and almond eyes (photos 1 and 2).

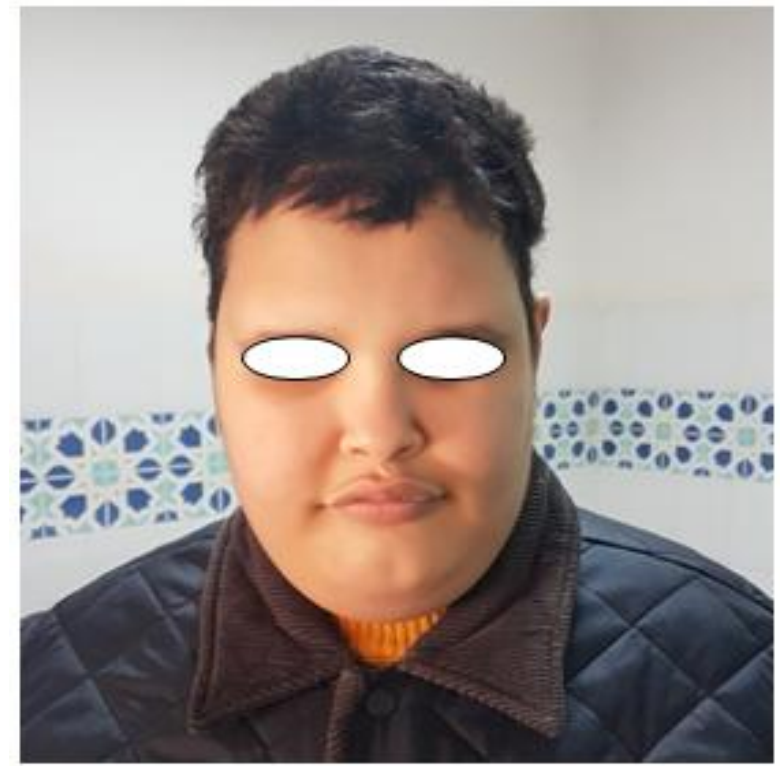

Photo-1: front view of our patient 


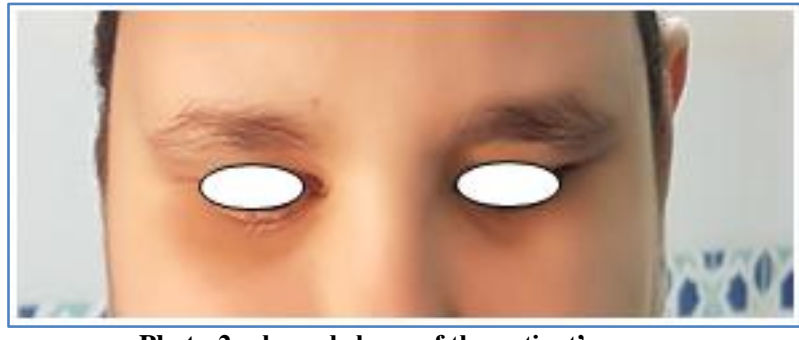

Photo-2: almond shape of the patient's eyes

Severe obesity started at the age of 4 , caused by hyperphagia and a decrease in basic energy expenditure. His current weight is $115 \mathrm{~kg}(253 \mathrm{lb})$ and is $1 \mathrm{~m} 45\left(4^{\prime} 7 \mathrm{ft}\right)$ tall (photo 3$)$.

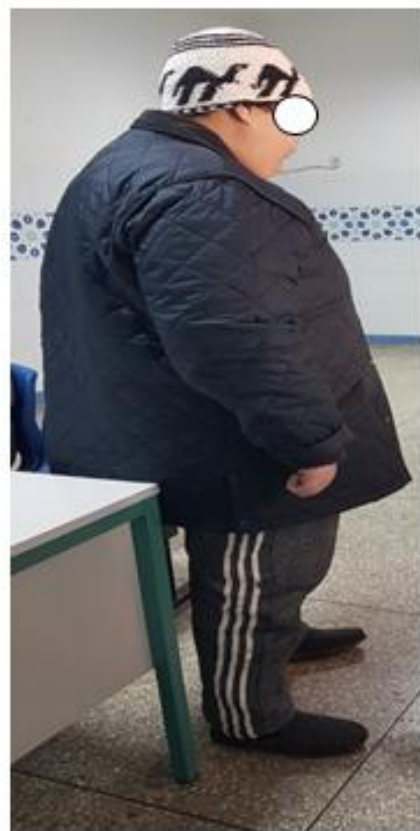

Photo-3: lateral view showing obesity and short height

Mr H.D has also a bilateral cryptorchidism, delay in size and puberty, intellectual deficiency and type 1 diabetes. He was referred by the endocrinology unit to the psychiatry department to take charge its behavioral disorders. The patient and family's examination has shown skin picking, temper tantrums, impulsivity, stubbornness, arguing with others, disobedience, lability, withdrawal, anxiety and obsessive compulsive features (food obsession and arranging). Despite high blood sugar test due to destabilized diabetes, other tests were normal (liver, kidneys, and electrolytes, thyroid)

A pharmacological treatment made of risperidone, SSRI and carbamazepine has been initiated and shown good results: decrease of impulsivity, stubbornness, temper tantrums, skin picking and anxiety, and less satisfying results with the food obsession.

A dietary approache has also been included three months after starting treatment: a reduced-calorie diet and increased physical activity, as well as close supervision around food and keeping food locked away. The results were remarkable. A weight loss of $12 \mathrm{~kg}$ (22lb) during 3months was noticed.

\section{DISCUSSION}

Although people with intellectual disabilities are at increased risk for psychiatric disorders, the type and rate of these problems differ between those with different causes for their retardation. On average, individuals with Prader-Willi syndrome function in the middle range of intellectual disability, wich means IQ: 60-70 [3, 4]. Importantly, individuals with Prader-Willi syndrome and higher versus lower IQs are just as vulnerable to the syndrome's characteristic hyperphagia and food seeking, as well as to behavioural difficulties[5]. Furthermore, despite the relatively high IQ of many with the syndrome, their day-to-day adaptive functioning often falls below their measured IQ, typically because of interference from food-related and other maladaptive problems. Behaviour problems in Prader-Willi syndrome are so salient that they have been included as a minor diagnostic criterion in the consensus clinical criteria for this syndrome [6]. As summarised in table I [7, 8] primary problems in children and adults with the syndrome. In addition to the syndrome's characteristic hyperphagia and food seeking, individuals with Prader-Willi syndrome also have increased risks of nonfood, compulsive behaviours. These include skin picking, which is highly prevalent, as well as more variable rates of hoarding, redoing and concerns with symmetry, exactness, cleanliness, ordering and arranging. Relative to others with mental retardation, patients with Prader-Willi syndrome are at a marked increased risk for developing full-blown, obsessive-compulsive disorder. In addition, many people with PWS show increased rates of tantrums, oppositionality and aggression [9].

Table-1: Percentage of 100 patients aged 4-46 years with Prader- Willi syndrome showing salient maladaptive behaviours

\begin{tabular}{|ll|}
\hline Behayiour & Percentage of patients \\
\hline Overeating & 98 \\
Skin picking & 97 \\
Stubbornness & 95 \\
Obsessions & 94 \\
Tantrums & 88 \\
Disobedience & 78 \\
Impulsiveness & 76 \\
Lability & 76 \\
Excessive sleep & 75 \\
Talking too much & 74 \\
Compulsions & 71 \\
Anxiety, worry & 70 \\
Preference for being alone & 67 \\
Getting teased a lot & 65 \\
Disliked by peers & 60 \\
Hoarding & 55 \\
Stealing (food, money for food) & 54 \\
Withdrawal & 53 \\
Unhappiness, sadness & 51 \\
\hline
\end{tabular}

Recent findings suggest that they also have an increased risk of psychotic disorder or affective illness with psychotic component especially young adult 
patients and those with the maternal uniparental disomy as opposed to paternal deletion. Symptoms of sadness and withdrawal seem more prevalent than full-blown affective disorder, and future work is needed to identify those risk factors that predispose some individuals to develop affective illness. [10] Other psychiatric disorders seem relatively infrequent in those with Prader-Willi syndrome. Even though many people with Prader-Willi syndrome steal food and are impulsive and distractible, clinically we find that rates are low for fullblown conduct or attention deficit hyperactivity disorder [11]. In contrast to those with other disorders, individuals with Prader-Willi syndrome infrequently experience fears or phobic disorders [12]. Some maladaptive behaviours or psychiatric problems may differ in frequency or severity across individuals with
Prader-Willi syndrome due to maternal UPD versus paternal deletion [13].

Medical management of Prader-Willi syndrome is largely problem oriented and, if obesity can be prevented, many children seem as healthy, if not healthier, than their unaffected siblings or age mates. Growth hormone therapy is increasingly used in children with Prader-Willi syndrome to target their short stature and poor muscle mass and tone [14]. A number of recent studies describing these positive effects contributed to the recent US FDA approval for using growth hormone to treat short stature in children with Prader-Willi syndrome [15]. The key behavioural management and intervention techniques for patients with Prader-Willi syndrome are outlined in table II.

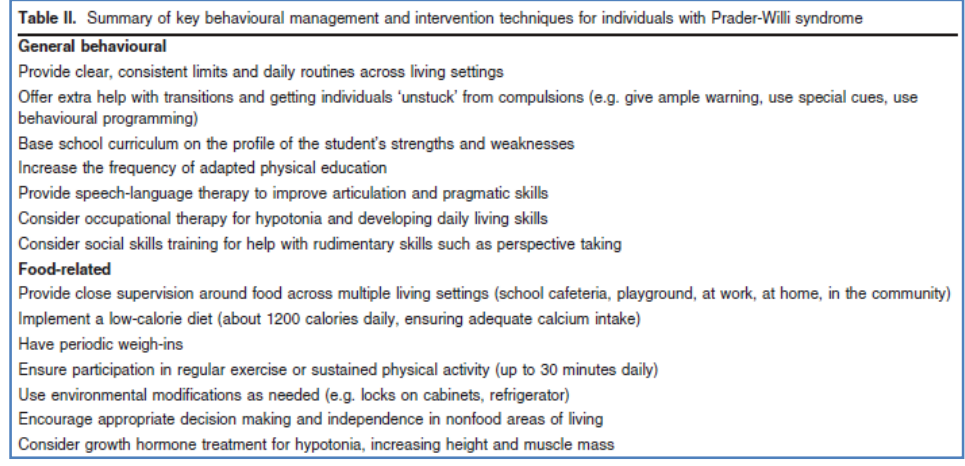

Although specific interventions vary by age and across individuals, most children with Prader-Willi syndrome benefit greatly from physical and occupational therapies to address hypotonia, as well as speech-language therapy to improve articulation and pragmatic skills. Further, many children and adults need social skills training, especially with rudiment skills such as turn taking and perspective taking [16].

To date, medications have not been successful in curbing the drive for food in individuals with PraderWilli syndrome, especially over the long term. Interventions continue to emphasise: a low-calorie diet (about 1200 calories a day, ensuring adequate calcium intake); periodic weigh-ins; regular exercise or physical activity (30 minutes a day is an appropriate goal); environmental modification as needed (e.g. locks on the cabinets or refrigerator); and close supervision to prevent access to food at school, on the job and in the community [17].

Psychopharmacological research in children and adults with Prader-Willi syndrome is quite limited, as it is with most other genetic mental retardation syndromes [17]. In Prader-Willi syndrome, a distinct advan- tage is that many studies now point to a unique behavioural phenotype characterised by hyper- phagia, compulsivity and other problems such as aggression and tantrums [18].
Food-seeking behaviours and bodyweight control are challenging areas to treat with drugs. The hyperphagia noted in Prader-Willi syndrome is more tightly linked with decreased satiation rather than increased hunger [19]. Therefore, appetite suppression medications such as CNS stimulants have not been helpful in curbing the hyperphagia associated with Prader-Willi syndrome. The possible exceptions to this rule are two drugs that are hypothesised to be anorectics but that are chemically unrelated to amphetamines: mazindol (anorectic agent that is likely to modify noradrenaline (norepinephrine) and dopamine metabolism [20]. The second agent showing some beneficial ef- fects in terms of food-related behaviour and body- weight loss is fenfluramine: a benzenethanamine and is structurally related to amphetamine, but CNS depression is more common than stimulation with fenfluramine, which makes it pharmacologically different from amphetamine[21].

Treatment for compulsivity and maladaptive behaviours include: behavioural programming; a structured, predictable routine; extra help with transitions; family support; and pharmacotherapy. Although formal drug studies have yet to be conducted, SSRIs have been effective in reducing a variety of symptoms linked to serotonin imbalance such as: skin picking, compulsivity, aggressive episodes, depression, self-injurious behaviour and anxiety [22]. Atypical antipsychotics have also proven helpful in persons with psychotic features or extreme aggression and 
impulsivity. Mood stabilisers such as lithium and antiepileptic drugs have been the treatment of choice for bipolar disorder and intermittent explosive disorder. Bipolar disorder is rarely seen in individuals with PraderWilli syndrome. There are two reports of carbamazepine trials involving individuals with PraderWilli syndrome, and showing good results in intermittent explosive disorders and violent outburst $[23,24]$.

Largely on the basis of case studies, the risks and benefits of these and other drugs in Prader-Willi syndrome are reviewed. Drug trials that move beyond case studies and that assess the relative efficacy of behavioural treatments alone or in combination with pharmacotherapy are sorely needed.

\section{CONCLUSION}

Prader-Willi's syndrome is a genetic disorder that affects in avarage $1 / 15000$ births. Psychiatric disorders are common, and the precocity of treatment can affects the prognosis. For the most part, pharmacological studies in Prader-Willi syndrome have yet to progress beyond open-trial case studies.

\section{REFERENCES}

1. Prader A, Labhart A, Willi A. Ein syndrom von aidositas, kleinwuchs, kryptorchismus und oligophrenie nach my- otonieartigem zustand im neugeborenenalter. Schweiz Med Wochenschr. 1956; 86: 1260-1

2. Butler MG, Meaney FJ, Palmer CG. Clinical and cytogenetic survey of 39 individuals with PraderLabhart Willi syndrome Am J Med Genet. 1986; 23: 793-809

3. Curfs LMG. Psychological profile and behavioral characteris tics in Prader-Willi syndrome. In: Cassidy SB, editor. Prader- Willi syndrome and other $15 \mathrm{q}$ deletion disorders. Berlin: SpringerVerlag. 1992: 211-22

4. Dykens EM, Hodapp RM, Walsh KK. Profiles, correlates, and trajectories of intelligence in PraderWilli syndrome. J Am Acad Child Adolesc Psychiatry. 1992; 31: 1125-30

5. Dykens EM, Cassidy SB. Correlates of maladaptive behavior in 35 children and adults with Prader-Willi syndrome. Am J Med Genet. 1995; 60: 546-9

6. Holm VA, Cassidy SB, Butler MG. Prader-Willi syndrome: consensus diagnostic criteria. Pediatrics. 1993; 91: 398-402

7. Dykens EM, Cassidy SB. Prader-Willi syndrome. In: Goldstein S, Reynolds CR, editors. Handbook of neurobehavioral and genetic disorders in children. New York: Guilford Press. 1999 525-54

8. Dykens EM, Leckman JF, Cassidy SB. Obsessions and compul sions in Prader-Willi syndrome. $J$ Child Psychol Psychiatry. 1996; 37: 995-1002
9. Clarke DJ, Webb T, Bachmann-Clarke JP. PraderWilli syndrome and psychotic symptoms: report of a further case. Ir J Psychol Med. 1995; 12: 27

10. Clarke DJ, Boer H, Webb T. Prader-Willi syndrome and psychotic symptoms. 1: case descriptions and genetic studies. J Intellect Disabil Res. 1998; 42: 440-50

11. Dykens EM, Leckman JF, Cassidy SB. Obsessions and compulsions in Prader-Willi syndrome. J Child Psychol Psychiatry. 1996; 37: 995-1002

12. Vitiello B, Spreat S, Behar D. Obsessivecompulsive disorder in mentally retarded patients. $J$ Nerv Ment Dis. 1989; 177: 232-6

13. Dykens EM, Cassidy SB, King BH. Maladaptive behavior dif- ferences in Prader-Willi syndrome due to paternal deletion versus maternal uniparental disomy. Am J Ment Retard. 1999;104: 67-77

14. Huffa BP. One year results of growth hormone treatment of short stature in Prader-Willi syndrome. Acta Paediatr Suppl. 1997; 423: 63-5

15. Lindgren AC, Hagenas L, Muller J. Effects of growth hormone treatment on growth and body composition in Prader- Willi syndrome: a preliminary report. Acta Paediatr Suppl. 1997; 423: 423-62

16. Hodapp RM, Freeman SFN, Kasari C. Parental educational preferences for students with mental retardation: effects of etiology and current placement. Educ Train Ment Retard De-velop Disabil. 1998; 33: 342-9

17. Dykens EM, Hodapp RM, Finucane BM. Genetics and mental retardation syndromes: a new look at behavior and interventions. Baltimore (MD): Brookes. 2000.

18. Selikowitz M, Sunman J, Pendergast A. Fenfluramine in Prader-Willi syndrome: a doubleblind, placebo-controlled trial. Arch Dis Child. 1990; 65: 112-4

19. Lindgren AC, Barkeling B, Hagg A. Eating behavior in Prader-Willi syndrome, normal weight, and obese control groups. J Pediatr. 2000; 137: 505

20. Itoh M, Koeda T, Ohno K. Effects of mazindol in two patients with Prader-Willi syndrome. Pediatr Neurol. 1995; 13 (4): 349-51

21. Fowles RE, Cloward TV, Yowell RL. Endocardial fibrosis associated with fenfluraminephentermine. N Engl JMed. 1998; 338 (18): 1316

22. Akefeldt A, Ekman R, Gillberg L. Cerebrospinal fluid monoamines in Prader-Willi syndrome. Biol Psychiatry. 1998; 44 (12): 1321-8

23. Tu J-B, Hartridge C, Izawa J. Psychopharmacogenetic aspects of Prader-Willi syndrome. J Am Acad Child Adolesc Psychiatry. 1992; 31: 1137-40

24. Gupta BK, Fish DN, Yerevanian BI. Carbamazepine for intermittent explosive disorder in a Prader-Willi syndrome patient. J Clin Psychiatry. 1987; 10:423. 